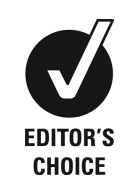

National Institute of Epidemiology (NIE), Chennai, Tamil Nadu, India

\section{Correspondence to} V Murlidhar, murlidharv@gmail.com

Accepted 27 May 2015

\title{
An 11-year-old boy with silico-tuberculosis attributable to secondary exposure to sandstone mining in central India
}

\author{
V Murlidhar
}

\section{SUMMARY}

Silicosis from secondary exposure is not often reported. This is the first such report of a child with possible silicosis attributable to secondary exposure to sandstone mining in India. Silicosis from secondary exposure has been reported in the gem polishing and slate pencil manufacturing industries in India; however, the stonemining industry is severely under-researched. No preventive measures have been instituted in the stonemining industry and children are exposed to respirable silica dust when their mothers take them to their work places. Poverty and lack of accessibility to modern medical facilities promote malnutrition and tuberculosis, two known co-morbid conditions. Stone mining, an export-oriented industry, produces billions of dollars of foreign currency every year. Although there is legislation to protect workers from exploitation, employers disregard the law and the state turns a blind eye by not implementing proper enforcement mechanisms. Silicosis from environmental exposure affects the entire community that lives in stone-mining areas.

\section{CASE PRESENTATION}

An 11-year-old boy in 5th grade in school attended a medical camp organised by a local NGO at Ganj Basoda in Madhya Pradesh in central India. He had a 4-year history of grade III dyspnoea on exertion. The boy is the youngest of seven siblings (4 brothers and 3 sisters). His father belongs to a Dalit community that traditionally works with bamboo, plays music in a band during weddings and festivals, and does not own any agricultural land. The family also earns income from goat rearing. The boy's mother started working in the mines soon after her marriage around 25 years ago. The family of nine lives close to the mines in a three-room house of bricks with one room reserved for the goats. The family resides in Badahar village in Ganj Basoda municipality in the central Indian state of Madhya Pradesh.

The boy's mother developed tuberculosis (TB) after the delivery of her first child and underwent treatment for 6 months. She had stopped working in the mines 1 year previously due to weakness, and was diagnosed with silicosis at the camp.

The boy has been malnourished since a young age. He was admitted to a Nutrition Rehabilitation Centre (facility-based care units in government hospitals for severe acutely malnourished children below 5 years of age) at an early age, where he also received treatment for $\mathrm{TB}$ for a month. Treatment was discontinued as he reportedly did not tolerate the medication. Although he has been attending school from the age of 6 , his attendance has been irregular. His mother denies taking him to the mines.

The boy had dry cracked skin all over the body. His weight and height were on the 3rd percentile (WHO Reference 2007 for 5-19 years). He had hepatosplenomegaly suggestive of severe malnutrition and vitamin A deficiency (figure 1). He displayed decreased air entry in all zones bilaterally and had expiratory rhonchi. He did not have clubbing or oedema of his feet. His cardiovascular system was normal.

\section{Investigations}

Sputum examination showed the presence of tuberculosis acid-fast bacilli and his blood count was unremarkable. Other tests could not be performed due to logistic and financial constraints. His chest $\mathrm{x}$-ray showed opacities suggestive of silicosis (ILO grading $\mathrm{r} / \mathrm{r}, 3 / 3$ ) and associated progressive massive fibrosis bilaterally (ILO grade C) (figure 2).

The diagnosis was pulmonary tuberculosis with suspected silicosis due to secondary exposure in a malnourished child. However, the diagnosis of silicosis is unconfirmed and difficult to determine at this time.

\section{GLOBAL HEALTH PROBLEM LIST}

- There are few epidemiological studies of the mining industry in India.

- The miners work under exploitative conditions and their families live in severe poverty with no access to health services.

- Families live close to the mines and are prone to developing silicosis from secondary exposure.

- The mining industry is an under-regulated sector marked by lack of enforcement which is ignored by the government. Existing legislation which could protect miners is not enforced by the state.

- The recent media and state attention directed at occupational silicosis-related deaths may lead to improved conditions for the miners. However, silicosis from environmental exposure continues to be ignored.

- The absence of environmental protection in the mines puts entire communities at risk of silicosis.

\section{GLOBAL HEALTH PROBLEM ANALYSIS}

The association between occupational exposure and silicosis has been well researched and studies 


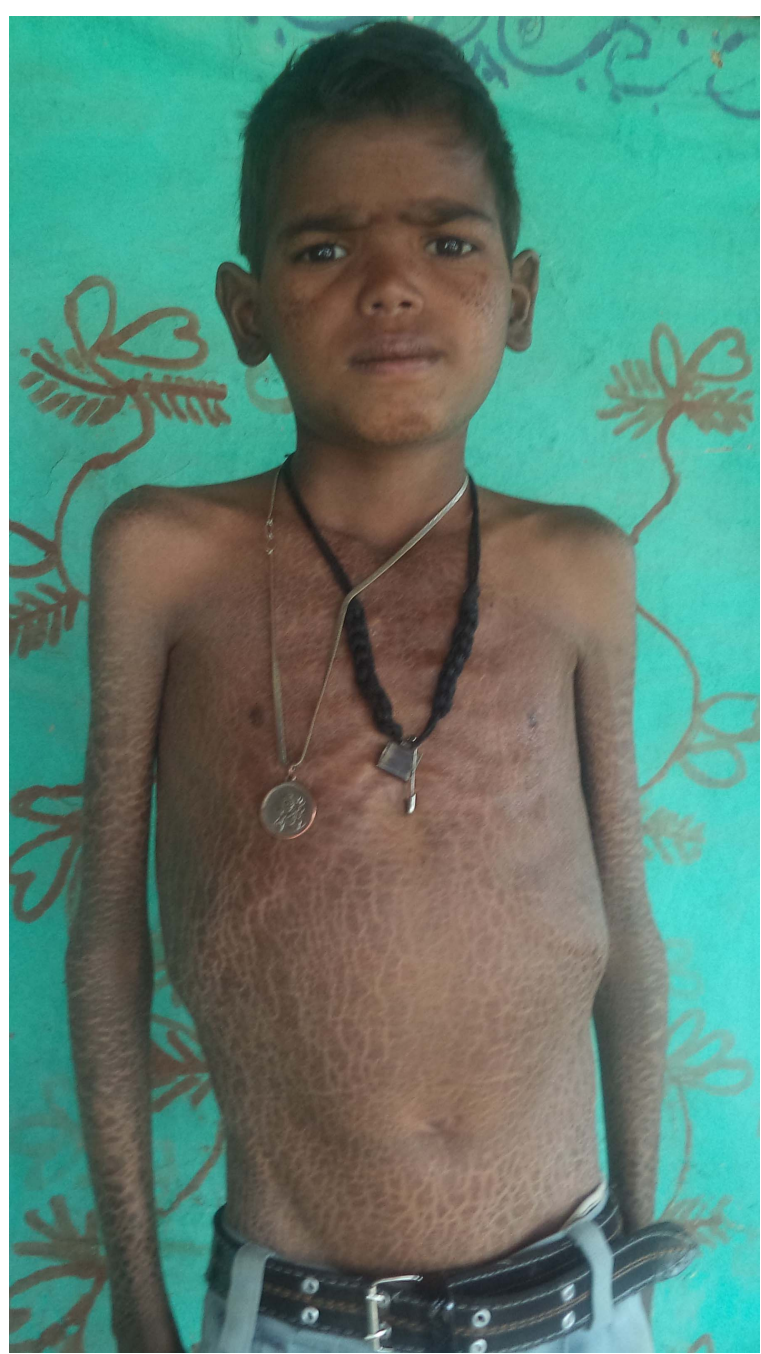

Figure 1 Frontal photograph of the patient showing hepatosplenomegaly suggestive of severe malnutrition and vitamin A deficiency.

have examined the prevalence of occupational silicosis in India. A study on the effects of mineral dust in young adults at an Indian stone mine found that they are particularly vulnerable to silica-laden dust which causes rapid deterioration of lung function. ${ }^{1}$ Cross-sectional studies by the National Institute of Occupational Health $(\mathrm{NIOH})$ and others have shown that the prevalence of silicosis among adult stone miners ranges from $12 \%$ to $21 \% .^{2-5}$ While silicosis from environmental exposure is under-researched and under-reported in general, silicosis from environmental exposure has been reported in the agate gem polishing and slate pencil industries in India. 67

There are very few epidemiological studies on the mining industry in India even though the sector has provided a livelihood for tens of thousands of Indians for centuries. ${ }^{89}$ There are no reliable data on the numbers of stone miners in India, the levels of dust at work sites, or baseline lung function among miners. ${ }^{10}$ Furthermore, there has been no study on silicosis caused by environmental exposure in mining areas, which affects the mining workers' families and communities. According to the report of the Indian Council for Medical Research (ICMR) (1999), about 3 million workers in India are at high risk of exposure to silica. Of these, 170000 are engaged in mining/ quarrying activities, 630000 in the glass and mica industry, and 670000 in the metals industry. ${ }^{11}$ The ICMR report does not

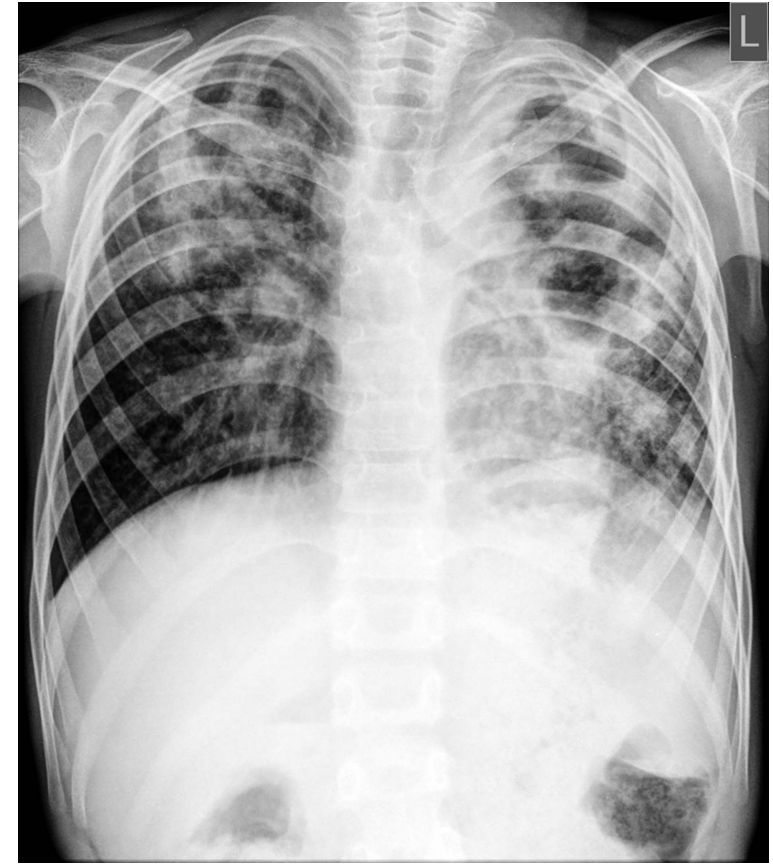

Figure 2 Chest X-ray posteroanterior (PA) view showing opacities suggestive of silicosis (ILO grading $r / r, 3 / 3$ ) and associated progressive massive fibrosis bilaterally (ILO grade C).

include family and community members exposed to secondary dust. As the average household size is estimated to be around 5.4 in rural areas, approximately 10 million people are affected by mining activities in India. ${ }^{12}$

Most of the work is carried out by unorganised labour, which lacks power for collective bargaining; exploitation by mine owners is therefore the norm. ${ }^{8}{ }^{11}$ The work sites have no dust control in place and many women and children work at wages below that stipulated by law. ${ }^{13}$ None of the mines provide safety gear for workers, who are continuously exposed to dangerous silica dust which they also take back with them into their homes, thus exposing their children and families. It is not uncommon for women workers to bring their infants and young children to the mines. Childcare facilities are non-existent and children are left under makeshift shelters just outside the mines while the mothers work, thus exposing them to dust at a very young age. Poor nutrition due to low wages, poor working conditions, and lack of access to healthcare and social security results in ill health and debt that begins early in the lives of those working in the mines in these areas. The association between silicosis and tuberculosis and malnutrition is well established. ${ }^{14}$ The nearest primary health centre may be many kilometres away. These deplorable conditions are prevalent in the majority of stone mines in India. ${ }^{13}$

The environment around stone quarries contains high levels of respirable silica dust. One study has shown that the ambient air content of respirable dust is higher than the legal limit at locations as far as $500 \mathrm{~m}$ from a stone crushing site. ${ }^{10}$ The families of many miners live close to the mines, and are thereby exposed to additional sources of silica-laden dust. ${ }^{13}$ There are no dust-suppressing controls at work sites in India. ${ }^{13}$

Poverty and minimal support systems compel many mothers in India to bring their children to the unsafe environment of the mines, where there are no childcare or primary healthcare facilities. ${ }^{13}$ However, the young boy in our case was allegedly not taken to the mines, but he has developed silicosis. While 
tuberculosis in conditions of poverty must have been a contributory factor, the fact that he developed the disease without being physically present at a mine indicates that the silicosis was caused by environmental exposure. The disease is compounded by his severe malnutrition and lack of access to modern medical services. This case flags the possibility of a high incidence of environmentally acquired silicosis among children in similar circumstances.

The main statute governing miners' health and safety is the Mines Act, 1952, which is administered by the Directorate General of Mines Safety (DGMS), an organisation under the Union Ministry of Labour. The Mines Act, along with the Factory Act, lays down regulations to protect miners. ${ }^{15} 16$ The Factory Act stipulates that children under the age of 14 are prohibited from being employed in mines. Significantly, Section 45 of the Mines Act 'prohibits [the] presence of any person below 18 years of age' in any part of a mine above ground where any operation connected with or incidental to any mining operation is being carried out. Nevertheless, child labourers (children between 10 and 16 years of age) constitute a high $10 \%$ of the workforce in the area and are grossly underpaid. Welfare, health and medical surveillance, and worker participation in safety management are also covered in the Mines Rules, 1955.

Reports have shown that environmental guidelines and regulations fail to protect communities from exposure to silica dust. Regulation 124 of the Metalliferous Mines Regulations, 1961 formulated under the Mines Act, 1952 prescribes the permissible limits for various types of airborne respirable dusts, including silica, dust sampling strategies, and control and surveillance measures that must be adopted in mines. ${ }^{17}$ Detailed provisions address how to prevent the release, accumulation and propagation of dust. Enforcement is the responsibility of state pollution control boards that issue guidelines and terms and conditions for the operation of industrial units including siting guidelines and emission standards under the Environment (Protection) Act, 1986 and the Air (Prevention and Control of Pollution) Act, 1981. ${ }^{17}$ Although the details of guidelines may differ from state to state, the main features are similar and include provisions for pollution control measures and standards. The mining companies can therefore be held liable for not maintaining standards and be forced to compensate for the harm done to the families and communities who develop silicosis from environmental exposure.

Despite a sound legislative framework, the occupational health of hundreds of thousands of mineworkers, if not their communities, remains elusive. The only body responsible for monitoring and enforcing the provisions of the Mines Act, 1952-the DGMS-lacks manpower, a monitoring and reporting infrastructure, and inspection planning. There are tens of thousands of smaller mines in the country who have not even registered with or do not report to the DGMS, as legal penalties for not doing so are weak and there are almost no prosecutions. As a result, these mines do not employ managers or trained medical practitioners to conduct regular check-ups or report notified diseases, and do not follow safety norms. ${ }^{18}$ The lack of active interest within the Indian state to even enforce existing laws to protect workers' health and safety can be attributed to the fact that mining is a major source of foreign exchange. Between April and December 2014 alone, India earned 1 billion INR from mining. ${ }^{19}$

Meanwhile, there have been widespread media reports on silicosis-related deaths. Media coverage of deaths in the Indian states of Gujarat and Madhya Pradesh in 2004-2005 in particular alerted the country's National Human Rights Commission
(NHRC) to the dangers of silicosis. The NHRC described silicosis as a 'serious occupational hazard', 'a health issue' and a 'human rights issue'. ${ }^{20}$ It also expressed consternation that 'in all cases, it is the poor labourer working in the unorganised sector who [is] the victim', which excludes them from labour protection and government schemes for the organised sector. It formed a National Task Force and, later, an Expert Group to generate a set of recommendations that took into account all aspects of the disease. The Commission also initiated hearings on the various petitions brought before it by NGOs in various states. A writ petition ((civil) no: 110/2006) filed by a Delhi-based NGO, which NHRC has also joined, is currently before the Supreme Court. While the case is still being heard, the Supreme Court issued an interim order in 2009 directing the NHRC to facilitate compensation for confirmed deaths due to silicosis. NHRC was also directed to engage with state governments and find means to rehabilitate and provide healthcare support for patients with silicosis. The Expert Group's recommendations have been sent to the Chief Ministers of all states. Some states like Rajasthan have set up systems for diagnosis and compensation, but many others have still not done so.

In 2008, the central government launched a smart card-based, cashless health insurance scheme with cover provided for 30000 INR per annum called the Rashtriya Swasthya Bima Yojana (RSBY), which was extended to mineworkers, among other categories, in 2013. ${ }^{21}$ However, the poor have not received sufficient coverage under this scheme and there is low awareness among beneficiaries about entitlements. It has also yet to be seen how RSBY will be extended to those working in mines not registered with the DGMS.

However, these changes, which are an essential step in the right direction, are only aimed at occupational exposure to silicosis. Silicosis from environmental exposure has not received any attention. Therefore, case reports such as this are crucial to bring attention to the critical and dangerous consequences of mining operations that affect entire communities and regions.

\section{Learning points}

- Silicosis due to secondary exposure can occur among the children of mining communities in India.

- Malnourishment, tuberculosis and silicosis are co-morbid conditions, especially in vulnerable populations like children who live close to stone mines.

- Children are especially vulnerable to silicosis from non-occupational exposure in stone-mining areas where (a) populations are very poor and have little access to modern medical facilities, (b) families live close to the work place and casual child labour is common, and (c) preventive measures are not taken by mine owners.

- Although mine owners do not comply with legislation to protect the health and safety of workers, the state ignores this situation as the stone-mining industry generates much foreign exchange, and there is limited legislative protection for families from secondary exposure.

Acknowledgements I wish to acknowledge Vasanthi Venkatesh and Sowmya Sivakumar for proof reading the article. Vasanthi Venkatesh helped to answer the critical comment from the editor regarding the extent of child labour in the mining industry in India by providing relevant references. 
Competing interests None declared.

Patient consent Obtained.

Provenance and peer review Not commissioned; externally peer reviewed.

\section{REFERENCES}

1 Green DA, McAlpine G, Semple S, et al. Mineral dust exposure in young Indian adults: an effect on lung growth? Occup Environ Med 2008;65:306-10.

2 National Institute of Occupational Health. Pilot survey of stone quarry workers in Jakhlaun area of Lalitpur district (U.P.). Ahemedabad: National Institute of Occupational Health, 1987:37-51.

3 National Institute of Occupational Health. Evaluation of health hazards in quartz crushing industry and evaluation of dust control measures. Ahemedabad: National Institute of Occupational Health, 1986:1-22.

4 Saini RK, Yousuf M, Allaqaband GQ, et al. Silicosis in stone-cutters in Kashmir. J Indian Med Assoc 1984;82:198-201.

5 Gupta SP, Bajaj A, Jain AL, et al. Clinical and radiological studies in silicosis: based on a study of the disease amongst stone-cutters. Indian J Med Res 1972;60:1309-15.

6 Bhagia LJ. Non-occupational exposure to silica dust in vicinity of slate pencil industry, India. Environ Monit Assess 2009;151:477-82.

7 Bhagia LJ. Non-occupational exposure to silica dust. Indian J Occup Environ Med 2012;16:95-100.

8 ICMR Bulletin. Silicosis - an uncommonly diagnosed common occupational disease. 1999;29(9).

9 Saiyed HN, Tiwari RR. Occupational health research in India. Ind Health 2004;42:141-8.
10 Sivacoumar $R$, Jayabalou $R$, Subrahmanyam $Y V$, et al. Air pollution in stone crushing industry, and associated health effects. Indian J Environ Health 2001;43:169-73.

11 National Conference on Silicosis. http://nhrc.nic.in/Documents/Background\%20Note \%20on\%20Silicosis.pdf (accessed Apr 2015).

12 CensusInfo India 2011: Houses, household amenities and assets. http://www. devinfolive.info/censusinfodashboard/website/index.php/pages/household_size/total/ Households (accessed Apr 2015).

13 Semple S, Green DA, McAlpine G, et al. Exposure to particulate matter on an Indian stone-crushing site. Occup Environ Med 2008;65:300-5.

14 Chaudhury N, Paliwal R, Phatak A. Co-morbidities among silicotics at Shakarpur: a follow up study. Lung India 2012;29:6-10.

15 Government of India. The Factories Act, 1948 (Act No. 63 of 1948), as amended by the Factories (Amendment) Act, 1987 (Act 20 of 1987).

16 Government of India. The Mines Act, 1952(Act No. 35 of 1952) (15 March 1952) (As modified up to 1983).

17 Legislative Provisions Relating to Silica Exposure and Silicosis in India: The Need for Review. http://www.okinternational.org/docs/Silica\%20Legislative\%20Review.pdf (accessed Apr 2015).

18 Ministry of Labour and Employment, Government of India. Planning Commission "Report of the Working Group on Occupational Safety and Health for the Twelfth Five Year Plan (2012-2017). August 2011.

19 Directorate General of Commercial Intelligence and Statistics, Ministry of Commerce and Industry, Government of India. India's export by principle commodities. http://www.dgciskol.nic.in/pdfs/emsft_04.pdf (accessed 25 Mar 2015).

20 National Human Rights Commission. Special Report to Parliament of India on Silicosis. 28 August 2011.

21 Extension of Rashtriya Swasthya Bima Yojana to other occupational groups. http://pib.nic.in/newsite/erelease.aspx?relid=96411 (accessed 24 Mar 2015).

Copyright 2015 BMJ Publishing Group. All rights reserved. For permission to reuse any of this content visit http://group.bmj.com/group/rights-licensing/permissions.

BMJ Case Report Fellows may re-use this article for personal use and teaching without any further permission.

Become a Fellow of BMJ Case Reports today and you can:

- Submit as many cases as you like

- Enjoy fast sympathetic peer review and rapid publication of accepted articles

- Access all the published articles

- Re-use any of the published material for personal use and teaching without further permission

For information on Institutional Fellowships contact consortiasales@bmjgroup.com

Visit casereports.bmj.com for more articles like this and to become a Fellow 